\title{
SINAIS E MARCOS DE ORIENTAÇÃO E ADVERTÊNCIA INDIGENAS
}

\author{
Frei Protásio Frikel OFM
}

Também o natural das selvas faz uso, em seus sertões iinóspitos, de sinais orientadores para a indicação de caminhos, viagens e outros fins. De certa maneira, constituem êles uma forma direta, embora bastante primitiva, de transmissão de mensagens, quer com sentido amistoso, quer hostil. Darei aqui algumas informações sôbre êsses sinais, que fiquei conhecendo entre os índios Kachúyana, tribo caraíba já bem dizimada do $\mathrm{R}$ io Trombetas, bem como as explicações que a respeito obtive dos próprios silvícolas.

Entre êsses sinais podem-se distinguir duas categorias: $10^{\circ}$ Sinais puramente indicativos de caminhos, referentes exclusivamente à orientação de vias ou rumos a serem tomados. São o osma yatótpere e o skarkátpere ou tskarkátpere. 2.0 Sinais informativos pessoais, ou seja, sinais que simbòlicamente representam pessoas e que, antes do mais, informam sôbre elas, podendo, contudo, não excluir o sentido da orientação de caminhos. São os kukúru.

\section{Sinais indicativos de caminhos}

Existem duas espécies de sinais de orientação, feitos, principalmente na mata, por meio de galhos ou pequenos arbustos quebrados - o osma yatótpere e o skarkátpere, respectivamente - e usados tanto nas viagens como nas caçadas, ou seja, sempre que os índios andam em grupos separados. Os que vão na frente, marcam o rumo e os que os seguem podem, desta forma, encontrar com facilidade o caminho certo ou os companheiros que os precederam.

a) Osma yatótpere. E' empregado onde existem picadas ou trilhos de caça ou caminhos de comunicação entre as malocas. Pcdemos considerá-lo adeqüadamente como um sinal de fechamento ou trave feito nas encruzilhadas ou nas bifurcações dos caminhos; como um sinal negativo de orientação que indica por onde não se deve transitar. Quebra-se um galho mais ou menos grosso ou corta-se uma árvore fina de modo a que atravesse o caminho errado, fechando-o. Quem segue atrás fica orientado e sabe que deve tomar o caminho "aberto". 
b) Skarkátpere. Enquanto o osma yatótpere é sinal de orientação em caminhos existentes, o skarkátpere o é na mata virgem, onde não existem trilhos. Assim, por exemplo, no ponto em que o caçador abandona a vereda de caça, primeiramente "fecha" o caminho com o osma yatótpere, indicando que aí terminou a sua marcha e que se desviou da vereda. A seguir, à medida que vai caminhando, vai quebrando um gatho ou arbusto pequeno, de forma que a ponta quebrada indique o rumo de sua marcha. Êste sinal é sempre feito quando se muda de rumo. Mas mesmo perfazendo trechos em linha reta, quando longos, de tempo em tempo se renova o skarkátpere. O caçador indígena está tão acostumado a usar êste sinal que não se esquece de realizá-lo mesmo correndo atrás da caça - porco, anta ou o que quer que seja. O skarkátpere tem, assim, dupla finalidade: é um marco para os companheiros que vêm atrás, permitindo-1hes seguir as pegadas com facilidade, e é também sinal de indicação de rumo para o próprio caçador em seu regresso, quando se aventura em zona nova e desconhecida.

Querendo-se mais uma vez destacar a relação entre êstes dois tipos de sinais, pode-se dizer que o osma yatótpere é um indicador de caminhos e estradas em áreas habitadas e conhecidas, enquanto o skarkátpere é, antes do mais, sinal de rumo em território sem caminhos.

\section{Os kukúru}

Um complexo de sinais de orientação um tanto diferentes e que se relacionam, principalmente, com pessoas ou suas atitudes, são os kukúru, têrmo que significa: imagem, figura, símbolo ou simplesmente sinal. Servem êstes kukúru, em primeiro lugar, para uma orientação em sentido amistoso, sendo, em geral, convidativos. Entre êles se encontra o chamado prêhnó kukúru, o "sinal da gente" ou "figura simbólica da gente", qưe por sua vez tanto pode ser um totó-kukúru, figura ou símbolo de homem, como um worêdz.-kukúru, figura de mulher. De outro lado, porém, existem, baseadas nestes mesmos conceitos de kukúru, expressões de uma atitude hostil ou, melhor, sinais de advertência ou ameaça. São o prauwekukúru, o sinal da flecha, e o kami-kukúru, o sinal de sangue, de que existem duas variantes: o sinal de sangue grande e o pequeno.

\section{a) Os kukúru convidativos}

Os kukúru consistem em paus ou varetas, mais ou menos retas e lisas, às vêzes descascadas, de cêrca de $1 \mathrm{~m}$ de comprimento, e que são fincadas no chão no meio do caminho, na porta, à frente ou mesmo dentro da casa. A vara simboliza a pessoa ou "gente", sem distinção de sexo, idade ou número. Donde seu nome mais genérico de prêhnó-kukúru ou "sinal, figura, símbolo de gente". No uso corrente, cada vara eqüivale a 
um indivíduo. Querendo-se especificar o número de pessoas, usam-se varetas em quantidade eqüivalente. Conforme o sexo: uma vara simples, lisa, significa "homem". E', então, totó-kukứru, ou seja, símbolo, figura, sinal de homem. Um kukúru amarrado pelo meio com uma fibra de fôtha de palmeira, simboliza a mulher. O sinal assim diferenciado chamase, então, worêdz.-kukúru ou seja, figura simbólica de mulher. Pode bem ser que esta diferenciação pela fôlha de palmeira provenha do costume de, em viagem, ser a mulher índia quem carrega o panacu ou jamachim, feito de palha, de sorte que a palha nas costas se teria tornado a expressão típica da mulher viajante. As crianças em geral não são indicadas ou, se crescidas, são mencionadas segundo a forma já relatada, como homens ou mulheres. Se houver necessidade de especificar as crianças com precisão, fincam-se junto ao grande worêdz-kukúru outras varetas, totókukúrü ou worêdz.-kukúru pequeninos, conforme seu número, o que é interpretado como a mãe com os respectivos filhos, meninos ou meninas.

Digno de menção é ainda o modo pelo qual êsses kukúru são fincados. Verticais, significam que as pessoas em aprêço estão presentes e se acham perto, na redondeza. Inclinados, porém, indicam a direção do local em que as pessoas representadas se encontram e devem ser procuradas.

O prêhnó-kukúru pode, por vêzes, expressar a idéia de coletividade ou totalidade (principalmente nos sinais de advertência, como depois ve$r \in m o s)$. Neste caso, usa-se uma vara ou pau mais grosso, de cêrca de 10 a $20 \mathrm{~cm}$ de diâmetro, que exprime a idéia de casa, clã, tribo, conjunto de homens, guerreiros etc.

Apresentaremos agora alguns exemplos práticos, explicativos, fornecidos pelos próprios Kachúyana.

Suposição: 3 homens e 2 mulheres vão em visita a parentes ou amigos de outra maloca ou passam, no percurso de uma viagem, por uma maloca conhecida. Acontece, porém, que os moradores estão ausentes. No momento da partida, deixam, para noticiar a sua visita, estada ou passagem, os prêhnó-kukúru fincados quer dentro da casa, quer em determinada bôca de estrada, quando existem vários caminhos que saem da aldeia para o interior. Os próprios índios desenharam-me o esquema reproduzido na fig. 1. A representação pode ser interpretada da seguinte maneira: 3 totó-kukúru e 2 worêdz.-kukúru no caminho que segue o rumo da serra. Ou seja: passaram por aqui duas famílias, 3 homens e duas mulheres, que continuaram viagem pelo caminho da serra. Dessa forma, os habitantes da maloca ficam logo informados, em seu regresso, de que os transeuntes eram amigos, conhecidos ou, pelo menos, gente de paz. O aviso os tranquiliza caso lhes faltem alguns objetos (digamos, uma peneira ou uns rolos de massa de mandioca) que os viajantes tomaram emprestados para a viagem. A dedução de que se trata de duas famílias é tirada da ordem ou do seguimento na colocação dos kukúru. Visto que 

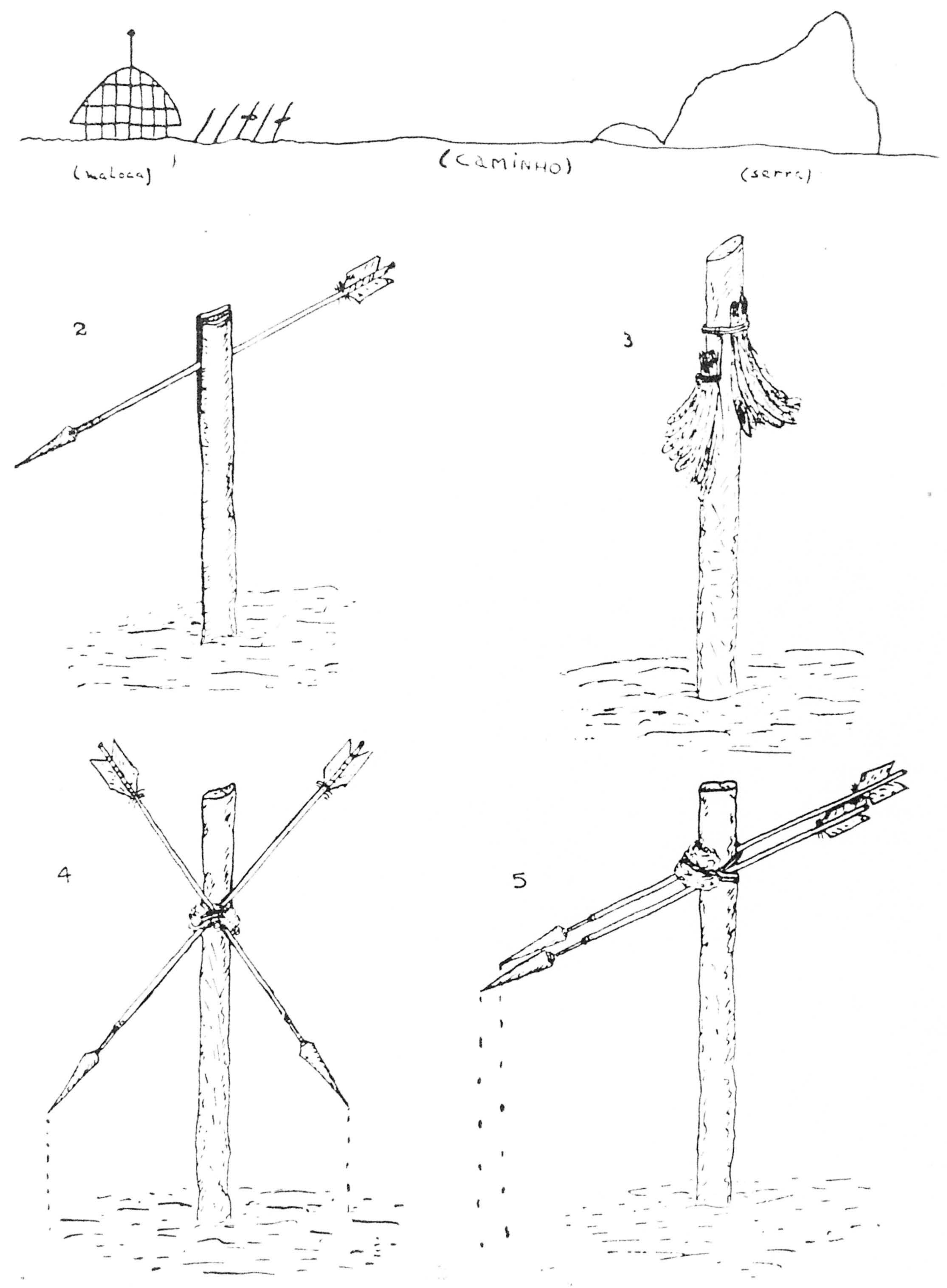
na marcha normalmente a mulher indígena precede o homem, a seqüência mulher-homem-mulher-homem-homem revela que se trata de duas famílias, a segunda provàvelmente com um filho já adulto ou algum companheiro de viagem.

Além disso, o prêhnó-kukúru pode servir de aviso da parte dos moradores de uma maloca a outras pessoas.

Suposição: Alguém aguarda visita ou companheiros para uma viagem prèviamente combinada. Por qualquer motivo, a chegada dêsses companheiros tarda mais do que foi previsto. Não se querendo ou não se podendo mais esperá-los, deixa-se o prêhnó-kukúru dentro de casa, no caminho, no pôrto ou em outro lugar visível e apropriado, para indicar que se partiu e para onde se foi, mencionando-se inclusive aspectos circunstâncias, como, por exemplo, o número de pessoas que seguiram. Pelo número de varetas, os retardatários poderão, inclusive, saber se ainda há gente na maloca que lhes possa dar melhores informações.

Em se tratando de viagem em canoa, procede-se de modo semelhante. Fincam-se à beira do rio ou no pôrto os prêhnó-kukúru com as respectivas indicações, principalmente do rumo em que a viagem deve ser feita - rio-abaixo, rio-acima ou em sentido transversal do rio. Caso o pôrto ou ponto de saída fique longe da maloca, emprega-se um kukúru duplo: o primeiro, perto da casa, no caminho que conduz ao pôrto ou ao lugar das canoas, e o segundo, neste último local. Ou então, fecham-se todos os caminhos por meio do osma yatótpere, exceptuando-se aquêle que vai ter ao pôrto das canoas (que fica desempedido, "aberto"), lugar onde depois se encontra nova orientação na forma de outros kukúru mais explícitos.

O prêhnó-kukúru também pode ser de importância no caso da aproximação de estranhos. Suposição: Avistam-se índios (ou civilizados) desconhecidos no pôrto. Se forem notados a tempo pelos moradores da maloca distante, a reação pode ser de dois tipos. Supondo-se que a visita seja de paz, não havendo, portanto, motivo para alarma, as coisas se passam sem maiores conseqüências, permitindo-se a aproximação dos forasteiros. Se, porém, os desconhecidos forem numèricamente superiores e se se observar em sua atitude algo inquietante, receando-se encontros desagradáveis, ern geral se opta por uma retirada estratégica, quer desaparecendo simplesmente na mata virgem, quer, o que é mais freqüente, refugiando-se em maloca vizinha de parentes, para maior confôrto e segurança. Não havendo na retirada nenhuma intenção hostil, mas simples precaução, e desejando-se, apoiado no refôrço da maloca vizinha, entrar em contacto com os estranhos, falar ou até mesmo negociar com êles, finca-se no chão o respectivo sinal, na bôca da estrada que conduz ao lugar eni que se encontram no momento. As mais das vêzes é êsse sinal um prêhnó-kukúru coletivo, um pedaço de pau roliço, meio grosso, do comprimento de um kukúru comum, o qual, por sua grossura, ex- 
pressa a idéia de coletividade (casa, tribo etc.). Tal sinalização revela que, se os estranhos forem pacíficos, poderão seguir o caminho indicado e encontrar a gente tôda naquela maloca. Mas que, se agirem de má fé, deverão contar com a resistência de tôda a tribo. Para demonstrar a boa intenção de sua parte, "fecham" todos os caminhos secundários ou bifurcações com os osma yatótpere, deixando aberto apenas o caminho certo. Em tais casos, os forasteiros podem prosseguir sem mêdo ou receio de cilada, pois se trata de sinais amistosos, convidativos.

\section{b) Os kukúru de advertência}

Continuando na suposição acima formulada, pode acontecer, ao contrário, que de modo algum queiram receber os estranhos ou entrar em contacto com êles, com receio de danos ou inimizade, feitiço ou doenças. Para expressar essa atitude, fincam-se no caminho os sinais de advertência. São expressões de admoestação, de ameaça, de hostilidade, de um "alto lá!" e de uma ordem de retirada. Embora o Caraíba hoje em dia já não possua muitas qualidades guerreiras, tendo se tornado covarde e traiçceiro em seu modo de guerrear, atacando apenas quando em superioridade numérica, não deixa de conservar ainda certos costumes dos antepassados. Não mata sumàriamente o seu adversário real ou suposto, mas chama-lhe primeiro a atenção, ameaça-o com certos sinais amedrontadores e dá-lhe, de início, oportunidade para retirar-se (o que, em geral, mais the agrada). Neste ponto conservou ainda algo da tradição de guerra de seus ancestrais, que, em muitos aspectos, realmente conheciam o "fair play", mesmo na luta.

Geralmente o primeiro sinal de advertência e ameaça é o chamado prawe-kukúru ou "sinal de flecha". Consiste numa vareta mais forte, fincada no meio da estrada, em pé, para indicar parada forçada: "Alto lá!" Na extremidade superior, é fendida, e nesta fenda se encaixa uma flecha do tipo rahó, flecha de taquara (fig. 2). Na realidade, é uma flecha de caça destinada a animais maiores (porcos, antas etc.), mas serve também para a guerra. Se há tempo suficiente, fabrica-se para o prauwekukúru uma flecha especial, chamada kuhakpá, flecha de guerra, destinada exclusivamente a matar homens. A kuhakpá, que é também de taquara, distingue-se, porém, da flecha de caça tanto na forma, como na colocação da ponta. Sempre, porém, a ponta da flecha do prauwe-kukúru é tinta com urucu para simbolizar o sangue. A flecha é dirigida na direção da qual se esperam os estranhos ou inimigos. Êste prauwe-kukúru é quase sempre o primeiro "sinal de sangue" e de ameça; fala a linguagem clara de uma atitude hostil. Deve ser interpretado da seguinte maneira: "Para trás! Aqui estão os homens da tribo (símbolo: vareta grossa, coletiva; prêhnó-kukúru ou totó-kukúru coletivo) para barrar-vos o caminho com as armas (símbolo: flechas dirigidas contra os ádvenas, no meio do 
caminho), que se tingirão em vosso sangue (símbolo: a ponta de flecha vermelha de urucu)". Ou, mais precisamente, na expressão do índio Muí: "Vai-te embora ou minha flecha te come!...".

Ao conhecedor da mata e de seus habitantes, êste sinal é suficiente para que inicie a retirada. Mas, pode acontecer ou que não se veja o prauwe-kukúru ou que os invasores não levem a advertência muito a sério ou, ainda, que a tomem como rebate falso, sem conseqüências. O índio, porém, que vê no prosseguimento da marcha e na aproximação, depois dêsse primeiro aviso, uma atitude hostil, põe, então, um segundo marco de parada forçada ou caminho, o kamí-kukúru, ou "sinal de san. gue", que pode ser feito de dois modos, sendo designado ,conforme a variante, por ptchíne, ou seja, sinal de sangue "pequeno", ou por akáne, akánro, sinal de sangue "grande".

Também êste sinal de sangue pequeno consiste em um pau fincado no meio do caminho. Ao redor da vareta, no centro, são amarrados alguns tufos de penas de arara vermelha (kuyari), as quais, mais uma vez, exprimem a idéia de sangue (fig. 3). O modo de ler êste kamí-kukúru é o mesmo já mencionado; mas êle é mais insistente: "Alto! Aqui estamos nós, os homens da tribo (símbolo: o totó-kukúrú no meio da estrada). Para trás! Senão corre sangue! (símbolo: as penas vermelhas de arara)".

Mas existe, mesmo na opinião dos índios, gente "cabeçuda", que, atrevida demais, passa por cima de tôda e qualquer advertência e ameaça. A inobservância do praưve-kukúru e do kamí-kukúru dá ao índio a certeza da intenção hostil dos estranhos. Mesmo assim, o índio lhes dá ainda uma última oportunidade, na forma de uma admoestação que, ao mesmo tempo, eqüivale a uma declaração de guerra e sentença de morte. E' o "grande" sinal de sangue, kamí-kukúru akánro. Novamente, no meio da estrada, finca-se uma vara mais grossa. Mas desta vez, colocam-se duas flechas do já mencionado tipo rahó ou kuhakpá, em forma de cruz. Elas são encaixadas na fenda da madeira ou simplesmente amarradas ao lado, de modo a fecharem a estrada, enquanto suas pontas são inclinadas para baixo como que provindo da mata vizinha (fig. 4).

Uma variante dêsse tipo consiste numa colocação diferente das flechas. Neste caso, não são amarradas uma sôbre a outra, em forma de cruz, mas paralelamente, à direita e à esquerda do prêhnó-kukúru, endereçadas no rumo de onde devem vir os forasteiros (fig. 5). E', portanto, um prauwe-kukúru mais elaborado.

Em ambos os casos, porém, as pontas das flechas são abundantemente tintas com urucu e na emplumação ou também na ponta da amarração no prêhnó-kukúru coloca-se um novêlo de entrecasca bem desfiada, da castanheira de macaco (provàvelmente a Couroupita guyanensis). Ensopa-se bem êste novêlo com a seiva expremida da própria casca, misturada com água. Devido à colocação inclinada das flechas, o liqüído escorre lentamente, flecha abaixo, até a ponta, colorindo-se com o urucu, e "a flecha pinga sangue". Êste sinal é o último apêlo e significa: "Parem 
aqui ou corre sangue! As nossas flechas vos alvejarão de ambos os lados da estrada e vos matarão!...".

Pelo sentido, uso tradicional e aplicação atual dêsses kukúru, sejam êles sinais amistosos e convidativos, sejam ameaçadores e hostis, pode-se concluir que os Caraíba de outrora devem ter tido um amplo código de civilidade e honra guerreira, do qual os atuais kukúru provàvelmente não passam de fragmentos. De fato, os próprios índios contam que "os antigos", quer dizer, seus antepassados, possuíam e usavam muito maior número dessas convenções da mata, as quais, com o correr dos tempos, caíram em desuso e esquecimento. Aqui, como em muitos outros sŁtores, observa-se mais uma vez o murchar e a decadência de uma cultura condenada a extinguir-se, mesmo sem a influência direta da civilização moderna.

Especialmente os sinais de advertência hostil podem ser de interêsse, pois que permitem vislumbrar algo dos antigos costumes de guerra. Como se vê, pelos vários kukúru (prauwe- e kamí-kukúru) procura-se intimidar e amedrontar o inimigo real ou suposto. E obedecendo a êstes sinais, o adversário tem a retirada franqueada. Hoje, pelo menos, não agrada ao índio tomar a iniciativa de lutas e contendas e - diga-se de passagem - na maioria dos casos realmente emprega êsses sinais como rebate falso para enganar o adversário, especialmente quando se sente inferior, fraco e em posição desvantajosa.

Segundo a explicação dos Kachúyana, tanto os sinais indicativos de caminhos, como os kukúru pròpriamente ditos, são convenções "intercaraíbas". São entendidcs e usados por tôdas as tribos de seu mundo, que é o Rio Trombetas e seus afluentes. Outrossim, que êstes sinais são antiquíssimos, arraigados pela tradição, e de grande valor prático na vida nas selvas, revela-o o simples fato de, mesmo entre os caçadores amazônicos da população cabocla e semi-civilizada, de descendência indígena, o costume das marcações de caminhos e rumos (osma yatótpere; skarkátpere) se conservar até hoje em uso com o mesmo sentido e na mesma forma de execução encontrados entre os índios Kachúyana e outras tribos do Rio Trombetas. 